\title{
Understanding the Culture of Collaborative Attempts among Academicians in Malaysia
}

\author{
doi:10.3991/ijac.v3i2.1111 \\ Mahani Mansor, Nazira Osman, Surina Nayan, Latisha Asmaak Shafie, and Anis Maesin \\ Universiti Teknologi MARA (UiTM), Malaysia
}

\begin{abstract}
This paper attempts to understand the culture of collaborative attempts of language academicians who are members of communities of practice who share common professional activities. Participants of these communities of practice engage in a variety forms of collaborative attempts which include knowledge sharing via traditional means; conducting research, team teaching, mentoring, writing books and publishing articles, or online collaborative means; email, instant messaging, blogs, facebook, discussion groups and blogs. The paper discusses the trends of collaborative practices and the reasons for such collaborations.
\end{abstract}

Index Terms - collaboration, collaborative practices, communities of practices, language academicians, knowledge sharing

\section{INTRODUCTION}

Collaborative practices apparently have become significant features in an academic life in higher institutions of learning. Working collaboratively may now start to become a trend among some university lecturers. Collaborative works are both emphasized for learners and faculty members. Traditionally, university culture stressed on individual research and achievement of the faculty members, however, today they are encouraged to work collaboratively in a group or a team. The collaborative activities among faculty members may come in the forms of practices such as conducting research, team teaching, mentoring, writing and publishing of journal articles and books and sharing of knowledge via online means such as email, blogs and discussion groups.

Working collaboratively in an organization that is becoming more challenging proves to have certain benefits. Aside of promoting a good sharing and research culture, it can also minimize the loneliness of working individually and maximize support for one another in effort to develop research skills in an academic life. Furthermore, according to Garbett and Tynan-Yourn (2004), working collaboratively in a project can promote quality research outputs and increase research skills of new faculty members.

This paper investigates the collaborative practices among language lecturers in a higher learning institution in Perlis, Malaysia ( Universiti Teknologi MARA Perlis). The study aims at finding out the trends of collaborative practices of twenty seven language lecturers in the university. Questionnaires were distributed to 27 language lecturers in the university to obtain information about their collaborative working trends. The significance of the study is to shed some insights into the types of collaborative works that can be further encouraged and enhanced in teaching and for the benefits of the organizations.

\section{LITERATURE REVIEW}

Traditionally, teaching has always been treated as a personal journey. Teachers go into their own classrooms with lessons, i.e. materials and activities that they have planned themselves. However, teaching is a profession that has become increasingly demanding and complex. Educators in general are expected to do more than just teach. There are many problems that they also have to face, such as physical constraints, inability to sufficiently attend to students' needs and achieving learning effectiveness (Shen \& Huang, 2007). Therefore, there is a need for them to collaborate in performing and completing their tasks.

Among the most educationally significant aspects of teachers' lives and work are the relationships that they build with their colleagues (Hargreaves, 1992). When teachers collaborate with their colleagues, it means to share work, literally, to 'co-labor' and this idea of sharing work relates to both tasks and products. This means that whenever possible, learning tasks should be divided among group members, so that they share the work equally. Collaboration is really about sharing ideas, writing, thinking and distributing the work among members of a team such that everyone has a part and everyone helps make the project successful (http://commtechlab.msu.edu/ sites/letsnet/noframes/bigideas/b2/b2theor.html.

The key effective characteristics of collaborative practices at a company level, a team or an individual level involve shared leadership, common goals, shared process and framework, shared decision making, mutual responsibility, change resilience, network intelligence, flexibility and responsive, open communication and diversity in thinking.

(http://www.educationau.edu.au/jahia/webdav/site/myjahi asite/shared/papers/collabprinciples.pdf)

Another term which is a recent coinage that is synonym to collaboration is 'community of practice'. According to Wenger (1998), communities of practice are formed by people who are engaged in a process of collective learning. They share domains of human endeavor. Such domains refer to a tribe learning to survive, a band of artists seeking new forms of expression, a group of engineers working on similar problems, a clique of pupils defining their identity in the school, a network of surgeons exploring novel techniques, a gathering of first-time managers helping each other to cope, etc. He further described that communities develop their practice through a variety of methods including problem solving, requests for information, seeking the experiences of others, reusing assets, coordination and synergy, discussing developments, visit- 
ing other members, mapping knowledge and identifying gaps.

There are numerous benefits of collaboration among educators. These benefits are not only vital for the students, but they are just as important for the teachers themselves. When teachers work together, they can help each other to set teaching objectives, implement lessons and evaluate students' performance. They can share ideas and provide constructive feedback on their teaching. Starr (n.d.) puts these as combined strengths, experience, areas of expertise and mutual support among teachers. Furthermore, teachers can also gain benefits in terms of professional development.

One collaborative approach that teachers can employ is team teaching. One instance of this is to have two or more teachers with similar or diverse backgrounds working together in a particular classroom. In such classroom, collaboration of teachers can lower teacher-student ratio. This results in a higher quality of teaching. Teachers will also be able to answer students' queries more easily because there is more than one expert in the class. According to Wilson and Hobbs (2006), the teachers can provide students different viewpoints and thus encourage critical thinking in them.

Studies have shown that collaborative effort brings positive effects to teaching and students' learning. In a study by Lee and Smith (1996), it was found that students' academic achievement was greater in schools where teachers share high levels of collective responsibility for students' learning. Similar finding was also noted by Fullan (1991), where collaborative relationships were found to have positive impacts on students' learning. Shen and Huang (2007) showed that collaborative action research could give teachers greater breadth and depth in understanding their own pedagogical practice. Working together can make teaching more fun, as it can provide a fresh perspective to it. Teachers can maintain continuity in class in case of absence. This can ensure that students will not miss valuable class time if a teacher is not able to do so for a particular reason. Collaborating with colleagues can be a good way to initiate, manage and sustain one's teaching commitment as it encourages collaborative reflection.

Nayan, et. al (2009) in their research on Lecturers and collaborative learning find that $83 \%$ of the lecturers prefer to implement collaborative learning in their classrooms. Among the reasons given by them for implementing collaborative learning are it promotes learners' academic progress, improves learners interaction skills, encourage learners' intrinsic motivation and it is appropriate for use with small groups.

Despite its numerous advantages, many are reluctant to employ collaborative approach in teaching. Cheang (2009) finds that the lecturers themselves have problems. One of the problems that he highlights is the lecturers themselves may have fluency problems and as a result, they don't take initiative to start conversations in English with their students.

Collaboration demands time, flexibility, organization, energy, willingness and trust from all involved. Lack of time and lecturers' reluctance to take on additional activities are factors that hinder collaboration among educators. In addition, individual differences too can make collaboration difficult. For instance, teachers who are content driven and textbook-based could face difficulty in making thematic connections between content areas; thus, a barrier to collaboration resulted from their pre-set beliefs (Hoenbrink, et al., 1997). When teachers have strong personalities and beliefs, they will have their own ideas on perspective issues such as planning of lessons and validity of assessment; and these can have negative effects on collaboration. In fact, it has been found that teachers' shared beliefs are the fundamental building blocks to establishing collaborative practices (Cook \& Friend, 1995). Furthermore, in order for teachers to be able to achieve optimum collaboration among them, there are some criteria that must be met. Teachers must have respect for each other, inside as well as outside the classroom. Furthermore, equal relationship and commitment among all parties need to be ensured in order for collaboration effort to be effective.

In universities, lecturers do collaborate. Lecturers in higher learning institutions are familiar with this kind of practice where they usually team-up to do research together. When they do research they actually learn and discover new things. In addition, by doing collaborative work they tend to generate more ideas and complete the work faster since there will be many ideas generated from all the group members. Lecturers are like students. They teach and at the same time learn. Thus, when they do collaborative work, they learn at the same time. In other words, they are also involved in collaborative learning. According to Smith \& MacGregor (n.d.), "Collaborative learning represents a significant shift away from the typical teacher-centered or lecture-centered milieu in college classrooms. In collaborative classrooms, the lecturing/listening/note-taking process may not disappear entirely, but it lives alongside other processes that are based on students' discussion and active work with the course material. Teachers who use collaborative learning approaches tend to think of themselves less as expert transmitters of knowledge to students and more as expert designers of intellectual experience for students-as coaches or mid-wives of a more emergent learning process."

We cannot deny the fact that technology is important nowadays. Therefore, as we move forward in this globalization era, collaboration is accomplished through technology. Many educators and others who work in groups use computer-augmented collaboration tools. The most common tool for individual and group communication is e-mail. Besides that, in higher learning institutions especially, on-line forum does help students to communication with the lecturer and among the students themselves. Kabilan, M.K. (2003) in his research on collaborative practices of Malaysian English Language teachers in an online forum finds that there exists an indication of collaborative efforts among the teachers in the attempt to enhance their professional development and learning. They shared their knowledge, practices and experiences with others and thus confirming their beliefs and views of what an ideal practice or practices of teaching should be. These teachers also sought information that may help them with their professional as well as teaching and learning lives.

In summary, collaborative practices do benefit educators as well as students in study places. Since we are living in this globalization world that requires us to further widen our horizon in teaching and learning in order to acquire new knowledge, collaborative practice is one of the best ways to be adopted by us. 


\section{MEthodOLOGY}

The subjects of this study comprised of twenty-seven (27) language lecturers from Universiti Teknologi MARA Perlis (UiTM Perlis). 3 of them are language lecturers of the third language which is Mandarin while the others are all English language lecturers. The English language lecturers teach various English language courses such as English proficiency courses, English for Occupational Courses (EOP) and English for Academic Purposes (EAP). The Mandarin lecturers teach proficiency courses of the respective languages. All of the respondents have to be involved in teaching and also other administrative work such as invigilating, preparing exam questions, marking and finalizing students' marks. Apart from that, they also voluntarily and actively carry out research, prepare manuals and write reference books to improve their working profiles or to gain personal satisfaction. In addition, the newly-appointed lecturers have to do compulsory research for the purpose of job confirmation aside from teaching. Interestingly, many of these activities are carried out collaboratively. Thus, the foundations of this study are these research objectives:

1. To examine university language lecturers' preference for collaborative practices.

2. To identify the types of the collaborative practices.

3. To examine the reasons for collaboration.

A self-administered questionnaire was used as the instrument for collecting data to meet the needs of our purpose. The questionnaire consisted of closed-ended questions which were divided into three sections. Section One consisted of questions concerning respondents' background, Section Two consisted of questions covering respondents' aims, motivational factors, opinions of the benefits, contributions of the collaborative practices and Section Three consisted of questions relating to respondents' perceptions towards collaborative practices. The respondents' responses for Section Three of the questionnaire were ranked on a Likert Scale of (1) to (5) which indicates; (1) for strongly disagree, (2) disagree, (3) not sure, (4) agree and (5) strongly agree. Simple frequency count was used to analyze the data.

\section{FINDINGS AND DisCUSSION}

The levels of respondents' preference toward collaboration with their colleagues were investigated and grouped into three categories. Table 1 illustrates these categories of scores and the levels of preference.

TABLE I.

LEVELS OF PREFERENCE TOWARD COLLABORATION WITH COLLEAGUES

\begin{tabular}{|c|c|}
\hline Total of Scores & Level of Preference \\
\hline $90-110$ & High level of preference \\
\hline $50-89$ & Average level of preference \\
\hline $22-49$ & Low level of preference \\
\hline
\end{tabular}

In terms of preference toward collaboration with colleagues, it has been found that 4 respondents (14.8\%) had a high level of preference, 21 respondents (77.8\%) had an average level of preference, and none had a low level of preference. The results indicate that all the respondents practiced collaboration in their work place. This is illustrated in Table 2.

TABLE II.

OVERALL PREFERENCE TOWARD COLLABORATION WITH COLLEAGUES

\begin{tabular}{|c|c|c|}
\hline Preference & Frequency & Percentage \\
\hline Low & 0 & $0 \%$ \\
\hline Average & 21 & $77.8 \%$ \\
\hline High & 4 & $14.8 \%$ \\
\hline \multicolumn{2}{|c|}{ Mean: 78.52, Standard Deviation: 9.54} \\
\hline
\end{tabular}

The lecturers practice quite varied types of collaboration among them. As indicated by Table 3, conducting research (81.5\%) and writing articles (65.4\%) and writing manuals and books (63\%) are among the common collaborations practiced in the university. These activities are in line with the university's aspirations that encourage the lecturers to contribute their ideas in terms of writing and publications either individually or collaboratively.

TABLE III.

TYPES OF COLLABORATIVE PRACTICES

\begin{tabular}{|c|c|c|}
\hline No. & Types & Percentage \\
\hline 1. & Conducting research & $81.5 \%$ \\
\hline 2. & Writing articles & $65.4 \%$ \\
\hline 3. & Writing manuals and books & $63 \%$ \\
\hline 4. & Practicing team-teaching & $48.1 \%$ \\
\hline 5. & Writing blogs and websites & $25.9 \%$ \\
\hline
\end{tabular}

The findings on the general aims and reasons of lecturers' collaboration are illustrated in Tables 4 to 6 below. The highest number of participants, $81.5 \%$, chose 'to learn and share areas of interest' as one of the reasons why they practice collaboration with their colleagues. The second highest, 77.8\%, chose 'increase knowledge level'. 'Development of new knowledge' was the third, with 59.3\%. $55.6 \%$ of the respondents chose "transfer of best practices" as one of the reasons why they collaborate. Meanwhile, 44.4\% chose 'stimulate collaboration between experts'. Two other reasons interestingly obtained the same number of percentage, $40.7 \%$. These were 'deliver solutions for daily problems' and coordination of department activities and project'. $37 \%$ of the respondents chose "make new contacts and new friends, while $14.8 \%$ chose 'identification of experts'. Only $7.4 \%$ chose 'create synergy between branches', and no respondents agreed that collaboration can create 'independence of organizational and geographic boundaries'. Some respondents had also added other reasons which were not stated in the questionnaire of why they practice collaboration. They claimed that when they collaborate, they could lessen their burden of work. Some respondents also stated that by collaborating, they could cut down the amount time that they need to spend on a particular task.

TABLE IV

AIMS OF COLLABORATIVE PRACTICES

\begin{tabular}{|c|l|c|}
\hline No & \multicolumn{1}{|c|}{ Aims } & Percentage \\
\hline 1. & Learn and share areas of interest & $81.5 \%$ \\
\hline 2. & Increase knowledge level & $77.8 \%$ \\
\hline 3. & Development of new knowledge & $59.3 \%$ \\
\hline
\end{tabular}




\begin{tabular}{|c|l|c|}
\hline 4. & Transfer of best practices & $55.6 \%$ \\
\hline 5. & Stimulate collaboration between experts & $44.4 \%$ \\
\hline 6. & Deliver solutions for daily problems & $40.7 \%$ \\
\hline 7. & $\begin{array}{l}\text { Coordination of department activities } \\
\text { and projects }\end{array}$ & $40.7 \%$ \\
\hline 8. & Make new contacts and new friends & $37.0 \%$ \\
\hline 9. & Speed-up learning & $33.3 \%$ \\
\hline 10. & Identification of experts & $14.8 \%$ \\
\hline 11. & Create synergy between branches & $7.4 \%$ \\
\hline 12. & $\begin{array}{l}\text { Independence of organizational and } \\
\text { geographic boundaries }\end{array}$ & $0 \%$ \\
\hline
\end{tabular}

Table 5 illustrates findings on factors that motivate the lecturers to collaborate with others. The reason 'the idea of receiving information' had the highest percentage, $88.9 \%$. The second highest, $85.2 \%$, was the reason that the respondents would like to strengthen 'relationships with others'. 'Wanting to share information with others' had the third highest percentage, which was $74.1 \%$. Meanwhile, $40.7 \%$ chose 'anticipated reciprocity', and 'incentives', at $29.6 \%$. The lowest two were 'increased reputation', $18.5 \%$ and others, $3.7 \%$.

TABLE V.

MOTIVATIONAL FACTORS

\begin{tabular}{|c|l|c|}
\hline No. & \multicolumn{1}{|c|}{ Factors } & Percentage \\
\hline 1. & The idea of receiving information & $88.9 \%$ \\
\hline 2. & The relationships with others & $85.2 \%$ \\
\hline 3. & $\begin{array}{l}\text { Wanting to share information with } \\
\text { others }\end{array}$ & $74.1 \%$ \\
\hline 4. & Anticipated reciprocity & $40.7 \%$ \\
\hline 5. & The incentives & $29.6 \%$ \\
\hline 6. & Increased reputation & $18.5 \%$ \\
\hline 7. & Others & $3.7 \%$ \\
\hline
\end{tabular}

In terms of the advantages of collaboration with colleagues, the findings are illustrated in Table 6. The majority of respondents, $88.9 \%$, chose 'get access to valuable information'. This was followed by $70.4 \%$ who chose 'get access to a large network'. $66.7 \%$ of the respondents agreed that they could 'work efficiently' and also 'have better exposure' when they collaborate with others. Meanwhile, $59.3 \%$ and $55.6 \%$ of the respondents respectively agreed that they would 'be better experts' and 'be more productive' when they collaborate. The two reasons that had the least percentage were 'learn permanently', at $29.6 \%$, and 'have fun', $25.9 \%$.

TABLE VI.

ADVANTAGES OF COLLABORATIVE PRACTICES

\begin{tabular}{|c|l|c|}
\hline No. & \multicolumn{1}{|c|}{ Advantages } & Percentage \\
\hline 1. & $\begin{array}{l}\text { Get access to valuable informa- } \\
\text { tion }\end{array}$ & $88.9 \%$ \\
\hline 2. & Get access to a large network & $70.4 \%$ \\
\hline 3. & Work efficiently & $66.7 \%$ \\
\hline 4. & Have better exposure & $66.7 \%$ \\
\hline 5. & Be better experts & $59.3 \%$ \\
\hline 6. & Be more productive & $55.6 \%$ \\
\hline 7. & Learn permanently & $29.6 \%$ \\
\hline 8. & Have fun & $25.9 \%$ \\
\hline
\end{tabular}

Table 7 illustrates the reasons why respondents collaborate. It was found that the majority of the respondents, $85.2 \%$, felt that collaboration could 'give new insight and ideas'. $63 \%$ of the respondents agreed that collaboration could encourage 'quality improvement' in their work. $44.4 \%$ of respondents felt that collaboration would also result in 'process improvement'. In terms of 'customer satisfaction', $40.7 \%$ of the respondents agreed to this idea. The respondents also thought that collaboration could promote 'innovation services' and 'cost reduction', whereby $29.6 \%$ and $22.2 \%$ agreed to these respectively. Only $18.5 \%$ of the respondents believed that collaboration could increase ‘employer satisfaction' and $14.8 \%$ believed that it could enhance 'market development'.

TABLE VII.

REASONS FOR COLLABORATIVE PRACTICES

\begin{tabular}{|c|l|c|}
\hline No. & \multicolumn{1}{|c|}{ Reasons } & Percentage \\
\hline 1. & Give new insight and ideas & $85.2 \%$ \\
\hline 2. & Quality improvement & $63.0 \%$ \\
\hline 3. & Process improvement & $44.4 \%$ \\
\hline 4. & Customer satisfaction & $40.7 \%$ \\
\hline 5. & Innovation services & $29.6 \%$ \\
\hline 6. & Cost reduction & $22.2 \%$ \\
\hline 7. & Employer satisfaction & $18.5 \%$ \\
\hline 8. & Market development & $14.8 \%$ \\
\hline
\end{tabular}

\section{CONCLUSION}

The language lecturers in the university are involved in various types of collaborative practices which they may perceive as contributing to their academic and professional developments. As the findings suggest, most language lecturers prefer to work collaboratively in fulfilling the aims of the organization and obtaining personal academic satisfaction. Thus, it may be a sign for the university to consider more collaborative activities in the future. Even though the current practices of the Language Department and the university do involve collaborations such as assigning lecturers to be group facilitators for academic programs and students' development programs, the lecturers found that most of the time they were forced to complete the tasks individually as they may be pressed for time to fulfill the task. They may also face physical and communication barriers to work as a team. Therefore, the department and university should look into a more effective way to get the lecturers to collaborate better with each others. For instance, the lecturers may be given more time to sit together and plan for the programs as a team or more team teaching should be encouraged in the department and university. Thus, collaborations may be optimized. The language lecturers prefer collaborative activities as they may feel that by working collaboratively, they may not only obtain access to new information, insight and knowledge, but they can also enhance their social networking skills that can lead to improvements in their relationships with others which in turn may contribute to a more quality work in the organization. The study also hopes to shed some insights for further research on more collaborative opportunities preferred and by the lecturers not only in the department itself but also among departments, faculties and within the university as a whole. 


\section{REFERENCES}

[1] Cheang, E.K. Factors contributing to poor spoken English versus gender, courses and speaking English at home: Proceedings of the Conference on Language Learning and Teaching (COLT), 2009, Universiti Teknologi MARA Kedah. 2009.

[2] Collaboration: Principles and practices. [Online]. Available: http://www.educationau.edu.au/jahia/webdav/site/myjahiasite/shar ed/papers/collabprinciples.pdf. Retrieved December 24, 2009.

[3] Cook, L. \& Friend, M. Co-teaching: Guidelines for creating effective practices. Focus on Exceptional Children. 23(3), pp.2-16, 1995.

[4] Fullan, M. The New Meaning of Education Change. New York: Teachers College Press, 1991.

[5] Hargreaves, A. Cultures of teaching: A focus for change. Understanding Teacher Development. New York: Teachers College Press, 1992.

[6] Hoenbrink, J., Johnston, M. \& Westhoven, L. Collaborative teaching of a social studies methods course: intimidation and change. Journal of Teacher Education, 48(4), pp. 293-300, 1997. doi:10.1177/0022487197048004007

[7] Kabilan, M.K. Collaborative practices in an unmediated online TESL forum. [Online]. Available: www.melta.org.my/ ET/2003/2003_34.pdf. 2003. Retrieved March 12, 2009.

[8] Lee,V.E. \& Smith, J. “Collective Responsibility for Learning and Its Effectiveness in Achievement and Engagement for Early Secondary School Students.” vol.104(2), American Journal of Education. pp. 103-147, 1996. doi:10.1086/444122
[9] Nayan, S. et. al. Lecturers and collaborative learning: Proceedings of the Conference on Teaching and Learning ICTL), 2009, INTI University College. 2009.

[10] Shen, M. \& Huang, Y. Collaborative Action Research for Reading Strategy Instruction: A case in Taiwan. Electronic Journal of Foreign Language Teaching, 4(1), 2007, pp.108-121.

[11] Smith, B.L. \& MacGregor, J. T. What is collaborative learning? Available: http://learningcommons.evergreen.edu/pdf/collab.pdf. Retrieved March 12, 2009.

[12] Starr, T. Creating and Sustaining Collaborative Relationships Among Teachers. [Online]. Available: http://www.educ.uvic.ca/ epls/faculty/storey/starr.htm. Retrieved March 11, 2009.

[13] Teamwork Theoretical Rationale.[Online]. Available: http://commtechlab.msu.edu/sites/letsnet/noframes/bigideas/b2/b2t heor.html. Retrieved March 11, 2009.

[14] Wenger, E. Communities of practice: learning, meaning and identity. Cambridge University Press. 1998.

[15] Wilson, J.H. \& Hobbs, S.H. Team Teaching: Benefits, Challenges, and Considerations. PsychTeacher Electronic Discussion List. [Online]. Available: http://teachpsych.org/resources/e-books/ eit2006/eit06-07.pdf . 2006. Retrieved March 11, 2009.

\section{AUTHORS}

Mahani Mansor, Nazira Osman, Surina Nayan, Latisha Asmaak Shafie, and Anis Maesin are with Universiti Teknologi MARA (UiTM), Malaysia.

Manuscript received October 19, 2009. Published as resubmitted by the authors May $22^{\text {nd }}, 2001$. 